This item was submitted to Loughborough's Research Repository by the author.

Items in Figshare are protected by copyright, with all rights reserved, unless otherwise indicated.

\title{
Predicting corrosion rate in chilled HVAC pipe network: Coupon vs linear polarisation resistance method
}

PLEASE CITE THE PUBLISHED VERSION

https://doi.org/10.1016/j.engfailanal.2019.104261

PUBLISHER

Elsevier BV

VERSION

AM (Accepted Manuscript)

\section{PUBLISHER STATEMENT}

This paper was accepted for publication in the journal Engineering Failure Analysis and the definitive published version is available at https://doi.org/10.1016/j.engfailanal.2019.104261.

\section{LICENCE}

CC BY-NC-ND 4.0

\section{REPOSITORY RECORD}

Durrani, Faisal, Ryan Wesley, Vijithan Srikandarajah, Mahroo Eftekhari, and Steve Munn. 2019. "Predicting Corrosion Rate in Chilled HVAC Pipe Network: Coupon Vs Linear Polarisation Resistance Method". figshare. https://hdl.handle.net/2134/11246048.v1. 


\title{
Predicting Corrosion rate in Chilled HVAC Pipe Network: coupon vs Linear Polarisation Resistance method
}

\author{
Faisal Durrani ${ }^{\star 1}$ (f.durrani@lboro.ac.uk), Ryan Wesley ${ }^{1}$, Vijay Srikandarajah¹, Mahroo \\ Eftekhari ${ }^{1}$ and Steve Munn ${ }^{2}$ \\ 1 School of Architecture, Building and Civil Engineering, Loughborough University, Loughborough, UK. LE11 3TU \\ 2 Hevasure Ltd, Stancliffe House, Whitworth Road, Darley Dale, Derbyshire DE4 2HJ
}

\section{Abstract}

Research has been undertaken to predict corrosion rate of conveyance pipes used in an HVAC system. This work focuses on comparing the performance of a conventional corrosion predicting technique known as the "coupon method" versus a relatively modern technique called Linear Polarisation Resistance (LPR). An experimental study has been conducted by building a relatively modern rig that was representative of a realistic HVAC system. It was found that both the coupon method and the LPR probe predicted similar corrosion rates with a difference of $8.3 \%$ which is insignificant in practical terms. Four highly important in-situ scenarios were simulated for a water temperature range of $12-32^{\circ} \mathrm{C}$, and it was found that an LPR probe with corroded electrodes over-predicted corrosion rate by $20 \%$ compared to a clean LPR probe. Also, a probe in use for 2 months over-predicted corrosion by $44 \%$ which is a significant error. A pipe network dosed with inhibitor was observed to reduce the rate of corrosion by $50 \%$ and $25 \%$ for water temperature of $12^{\circ} \mathrm{C}$ and $32^{\circ} \mathrm{C}$ respectively. It was also determined that one degree $\left({ }^{\circ} \mathrm{C}\right)$ increase in water temperature will increase the corrosion rate by $3.5 \%$ on average. It has been identified that both coupon and LPR probes give similar results though both have limitations and continuous monitoring of corrosion is the way to insure a low maintenance HVAC pipe network.

\section{Keywords}

Corrosion, coupons, Linear Polarisation Resistance, Pipes, HVAC

\section{Introduction}

To mitigate climate change the UK government has set an ambitious target of reducing CO2 emissions by at least $80 \%$ of 1990 levels by 2050 . The buildings and buildings construction sectors combined are responsible for $36 \%$ of global final energy consumption and nearly $40 \%$ of total direct and indirect CO2 emissions. Around $60 \%$ of this energy is used for heating, hot water, and cooling. The UK domestic and industrial energy consumption in 2017 were 466,594 and 279,946 Megawatt hours (MWh) respectively (Department for Business, Energy, \& Industrial Strategy, 2018). Most the energy consumption in buildings is for the heating (45\%), Hot water (9\%) and cooling (5\%). Therefore, the energy used for HVAC in commercial and domestic buildings is around $59 \%$ of total building energy consumption. The HVAC industry can reduce energy consumption simply through making the important connection between proper maintenance, water quality and energy use within a wet Closed Loop/Hydronic Heating and Cooling system. 
Requirements for comfortable indoor environments in buildings have resulted in an increased demand for air conditioning. Strip away the building fabric and you will likely see long runs of pipes that transfer heat/coolth from the point of generation to the point of demand. These conveyance pipes form a closed-loop 'pipe network' where the fluid often recirculates continuously as long as the HVAC system is running. However, in pursuit of reducing energy demand of air-conditioning, the usual focus is either on the generation side (e.g. boiler/chiller) or on the dissipation side (e.g. heat exchangers). The performance of conveyance pipes (which make up majority of the entire HVAC system) is often overlooked which has great energy and economic savings potential.

The biggest cause of pipework failure is corrosion. The cost of protection against corrosion and corrosion failures is $£ 6.2$ billion in the United States alone (Fontana, 2005). According to the Hoar (1976) in England, corrosion losses amounted to $3.5 \%$ of the Gross National Product (GNP). Also, it is estimated that one-sixth of steel production all over the world is used to replace corroded metal which costs about 58 billion pounds annually. In 2016, it was estimated by industry leaders that about 40 $60 \%$ cost of pipe maintenance was due to corrosion under insulation. Corrosiondamaged tubes used in air-conditioning systems cannot work effectively and thereby cannot meet the users' requirements (Duncan, 2011). Thus, corrosion not only results in reducing comfort levels and productivity at work, but also leads to higher power consumption, maintenance costs and even the loss of commercial income during downtime. Accurate methods to measure and forecast corrosion would result in timely intervention and thus result in economic and energy savings. This study attempts to compare popular corrosion measuring techniques on a realistic yet fully controllable HVAC pipe network rig. The aim to quantitatively compare corrosion rate predicted by coupons vs an LPR probe and understand the conditions that affect an LPR reading as it's a dynamic corrosion measuring technique.

\section{Background}

Corrosion is commonly referred to as rust. BS EN ISO 8044 formally defines corrosion as "physicochemical interaction between a metal and its environment that lead to changes in properties of the metal, and which may result in the significant impairment of the function of the metal, the environment, or the technical system, of which these form a part" (Brown, 2013).

The process of corrosion for steel in neutral solutions is as follows:

Anodic oxidation reaction is:

Cathodic reduction reaction is:

$$
\mathrm{Fe}=\mathrm{Fe}_{2}{ }^{+}+2 e^{-}
$$

$$
\mathrm{O}_{2}+2 \mathrm{H}_{2} \mathrm{O}+4 e^{-}=4 \mathrm{OH}^{-}
$$

which is accompanied by the following: 


$$
\mathrm{Fe}^{2+}+2 \mathrm{OH}^{-}=\mathrm{Fe}(\mathrm{OH})_{2}
$$

then ferric hydroxide $(\mathrm{Fe}(\mathrm{OH}) 3)$ is formed by the combination of ferrous hydroxide with oxygen and water:

$$
2 \mathrm{Fe}(\mathrm{OH})_{2}+\mathrm{H}_{2} \mathrm{O}+\frac{1}{2} \mathrm{O}_{2}=2 \mathrm{Fe}(\mathrm{OH})_{3}
$$

Ferric hydroxide then turns into rust as $\mathrm{Fe}_{2} \mathrm{O}_{3}$ in the situation of dehydration (Lambert, 2001). The higher oxidation state, $\mathrm{Fe}(\mathrm{III})$ in the form of $\mathrm{Fe}_{2} \mathrm{O}_{3}$ is referred to as hematite whereas the lower mixed oxidation state $\mathrm{Fe}(\mathrm{II})$ and $\mathrm{Fe}(\mathrm{III})$ in the form of $\mathrm{Fe}_{2} \mathrm{O}_{3}$ is referred to as magnetite. In reality, both oxides are commonly present on the internal surface of steel pipes exposed to aerated water, although the ratio changes depending on the dissolved oxygen level of the water.

Mils per year (mpy) is the most desirable way to express corrosion rates related to penetration. It can be easily calculated using the 'weight loss' method using the following equation (Fontana, 1987):

$$
C=\frac{W \times K}{D \times A \times T}
$$

Where,

$\mathrm{C}=$ corrosion rate in mils per year (mpy)

$\mathrm{W}=$ weight loss (grams)

$\mathrm{D}=$ density of alloy $\left(\mathrm{g} / \mathrm{cm}^{2}\right)$

$A=$ exposed area of allow $\left(\mathrm{m}^{2}\right)$

$\mathrm{T}=$ exposed time $(\mathrm{hr})$

The K-factor can be deduced from Table 1.

Table 1: K-factor values for determining corrosion rate

\begin{tabular}{|c|c|c|}
\hline Desired Corrosion Rate Unit (CR) & Area Unit (A) & K-Factor \\
\hline Mils/year (mpy) & $\mathrm{in}^{2}$ & $5.34 \times 10^{5}$ \\
\hline Mils/year (mpy) & $\mathrm{cm}^{2}$ & $3.45 \times 10^{6}$ \\
\hline Millimeters/year (mmy) & $\mathrm{cm}^{2}$ & $8.76 \times 10^{4}$ \\
\hline
\end{tabular}

Corrosion rate units can be converted using the following relations:

$1 \mathrm{mpy}=0.0254 \mathrm{~mm} /$ year $=25.4 \mu \mathrm{m} /$ year $=2.9 \mathrm{~nm} /$ hour $=0.805 \mathrm{pm} / \mathrm{sec}$

Corrosion rates of materials generally range from 1 to $200 \mathrm{mpy}$. Corrosion rate can be divided into 6 grades corresponding to different ranges of corrosion rates which is shown in the Table 2. 
Table 2: Relative Corrosion resistance ranges for materials

\begin{tabular}{|c|c|}
\hline Relative corrosion resistance & mpy \\
\hline Outstanding & $<1$ \\
\hline Excellent & $1-5$ \\
\hline Good & $5-20$ \\
\hline Fair & $20-50$ \\
\hline Poor & $50-200$ \\
\hline Unacceptable & $200+$ \\
\hline
\end{tabular}

Corrosion not only affects conveyance pipes but also expensive and critical HVAC equipment such as pumps, boilers, heat exchangers. Clearly, the effects of corrosion on the world are not trivial. In practice the attitude towards corrosion is passive i.e. when a pipe fails due to corrosion it is simply replaced. However, the industry is trying to look for more active ways to predict corrosion in their pipe networks and take preemptive steps.

The most typical method is the corrosion coupons for predicting corrosion rate. The method involves suspending a metal coupon of the same material as the pipes into the pipe network and then taking it out and measuring its weight loss over a certain time period. The weight loss is then scaled to a corrosion rate developed by the coupon manufacturers.

The other and relatively modern, quick and non-destructive technique for measuring corrosion is the Linear Polarisation Resistance (LPR) method. It involves measuring the change in polarisation voltage and current between two metal tips suspended in an aqueous environment. The LPR probe then converts linear polarization resistance to an annual rate of metal loss (mils per year).

The aim of this research is to compare for the first time the performance of the LPR technique with the long-established coupon method in a realistic pipe network and investigate the factors which contribute to higher corrosion rates. It is intended that this research will clarify the best approach to measuring corrosion in practice and also understand how different in-situ scenarios affect corrosion rate prediction using the two methods.

\section{Methodology}

Conventionally, pipe performance experiments are conducted in two ways. The first method is to conduct experiments on a section of tube in benchtop rig setup. Although these experiments are good for comparison between two different pipes and provide insight into the properties of the pipe section, there are however limitations to this approach. A benchtop experimental setup is not representative of what happens in the field. Simulating a real HVAC pipe network becomes very difficult on a benchtop experiment. The other method is to conduct passive experiments where sensors are 
installed on real systems where relationships are drawn between cause and effect variables. These have limitations of their own as the entire system is never in control of the researcher and can only observe the system passively.

Thus, to research HVAC pipe performance that would be realistic yet fully controllable for research, an original representative HVAC pipe network rig was constructed. This wholistic building services rig was constructed specifically to focus on pipe performance in terms of corrosion.

\subsection{The Corrosion Rig}

The corrosion rig consisted of a network of parallel pipes connected via pipe fittings (bends, t-joints, valves etc) and is supported with the help of a metal framework. Water at a set temperature can be supplied to the pipe network with the help of a water chiller unit situated at the bottom of the rig. Other monitoring devices are installed at suitable locations to measure mass flow rate (flow meter), pressure (pressure transducers), $\mathrm{pH}$ $(\mathrm{pH}$ monitor) and sensors to measure room temperature and humidity. All the monitoring devices needed to be able to log data onto a computer that displayed the conditions of the rig in real time and plotted historic data. Important components in the rig are discussed in the following sections.

\subsubsection{Water Chiller}

The water chiller is installed at the base of the rig in order to circulate water at a desired temperature (Figure 1a). The chiller also has two supplementary roles to play which is to store the water in its tank and to pump the water through the pipe network. The chiller works on the vapour compression cycle and has the usual components; compressor, condenser, evaporator and expansion valve. The chiller also has a thermostat for setting the water temperature and a pressure gauge. Water temperature can be varied $8^{\circ} \mathrm{C}$ to $25^{\circ} \mathrm{C}$. The temperature of the water was logged by the on-rig PC.

\subsubsection{The flow meter}

The flow meter (Figure 1b) can calculate and display both flow rate and total accumulated flow. The flow transmitter can work in a wide range of temperatures. In this experiment, the flow transmitter is mainly used to measure and display the flow rate of water in the pipes and then transmit the data simultaneously to the computer where it will be stored.

\subsection{1. $\mathrm{pH}$ monitor}

Monitoring the $\mathrm{pH}$ of water circulating in the pipes is extremely important when researching corrosion. Typically, a pH paper is used to determine the $\mathrm{pH}$ level of a solution. However, in this case the system needed to be closed-loop where oxygen was not allowed to seep in nor could water be drained out hence the $\mathrm{pH}$ paper method could not be used. Additionally, the $\mathrm{pH}$ of the water needed to be monitored and recorded in real time. Thus, an electronic $\mathrm{pH}$ monitor (PHTX-45) was installed on the 
main feed line which can measure $\mathrm{pH}$ between 0 to 14 and displays temperature of water at the sensor's tip (Figure 1c). The pH monitor was mounted close to the HVAC outlet as it was considered to be the best location where the fluid will be mixed enough to give an average $\mathrm{pH}$ reading of the entire water in the rig. The water temperature measured by the $\mathrm{pH}$ sensor can also be compared with temperature measured by the water chiller. This comparison of temperatures is to check if both sensors are measuring water temperature at either end of the rig accurately. The PHTX-45 pH monitor was able to relay data measured with the on-rig PC.

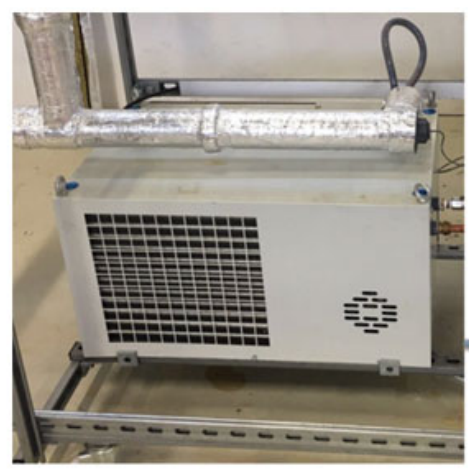

(a)

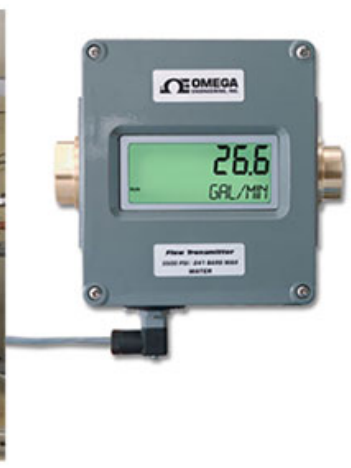

(b)

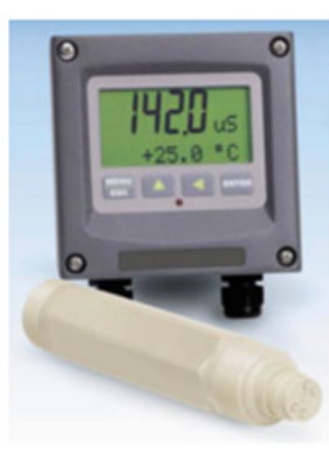

(c)

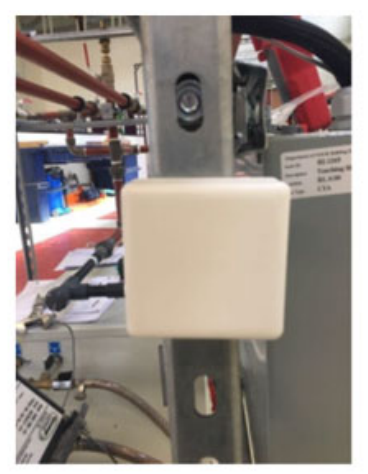

(d)

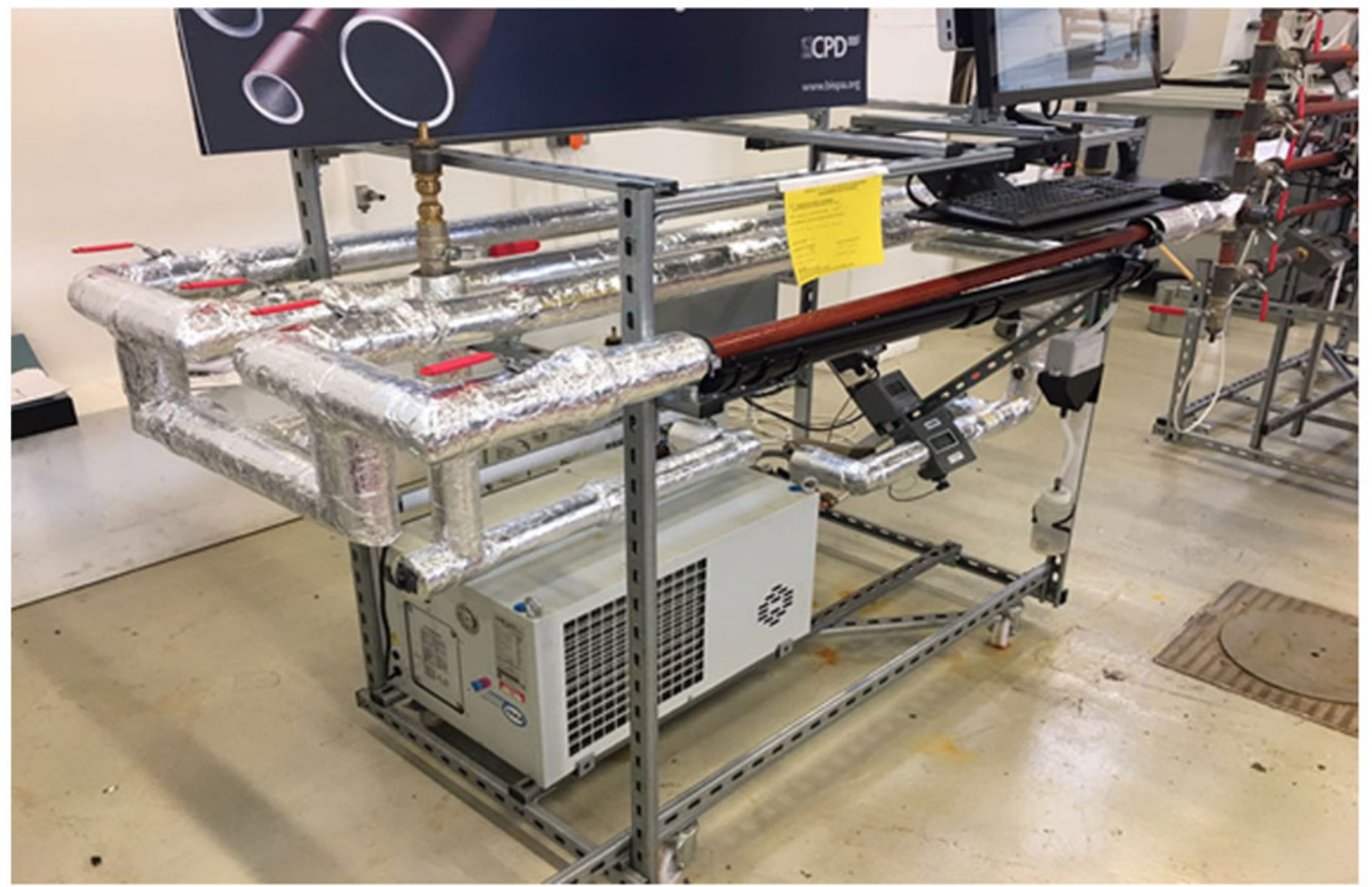

(e)

Figure 1: Major components of the corrosion rig: (a) The water chiller unit (b) flow meter (c) $\mathrm{pH}$ sensor $(\mathrm{d})$ room temperature and humidity sensor $(e)$ orthogonal view of the rig 


\subsubsection{Room temperature/humidity sensor}

The temperature and humidity sensors are situated in the same case and mounted on the side of the rig (Figure 1d). The temperature sensor had a range of $-30^{\circ} \mathrm{C}$ to $70^{\circ} \mathrm{C}$ which covered the temperature range of concern in this research. The humidity sensor can measure 0 to $100 \% \mathrm{RH}$ with a possible error of $\pm 2 \%$.

\subsection{Measuring Corrosion}

In this experiment the pipes under investigation are made of mild steel which is why the coupons were selected of the same material. It is also recommended to use two coupons at different locations to each other in the pipe network to get a good approximation of the corrosion rate. Coupons come in different shapes and sizes and are chosen based on the size and design of the pipe network. For the corrosion rig built in this research study, strip coupons were suitable and hence chosen.

The coupons were installed by screwing them onto holders (provided by the coupon manufacturers) and then screwing them into either ends of the rig such that the strip is mounted parallel to fluid flow and not perpendicularly (see Figure 2). One coupon is also mounted at a higher level in the rig whilst the other at a lower height in order to get a good overall corrosion rate. The coupons are handled with latex gloves when mounting as oils from the fingers can disturb the natural corrosion process.
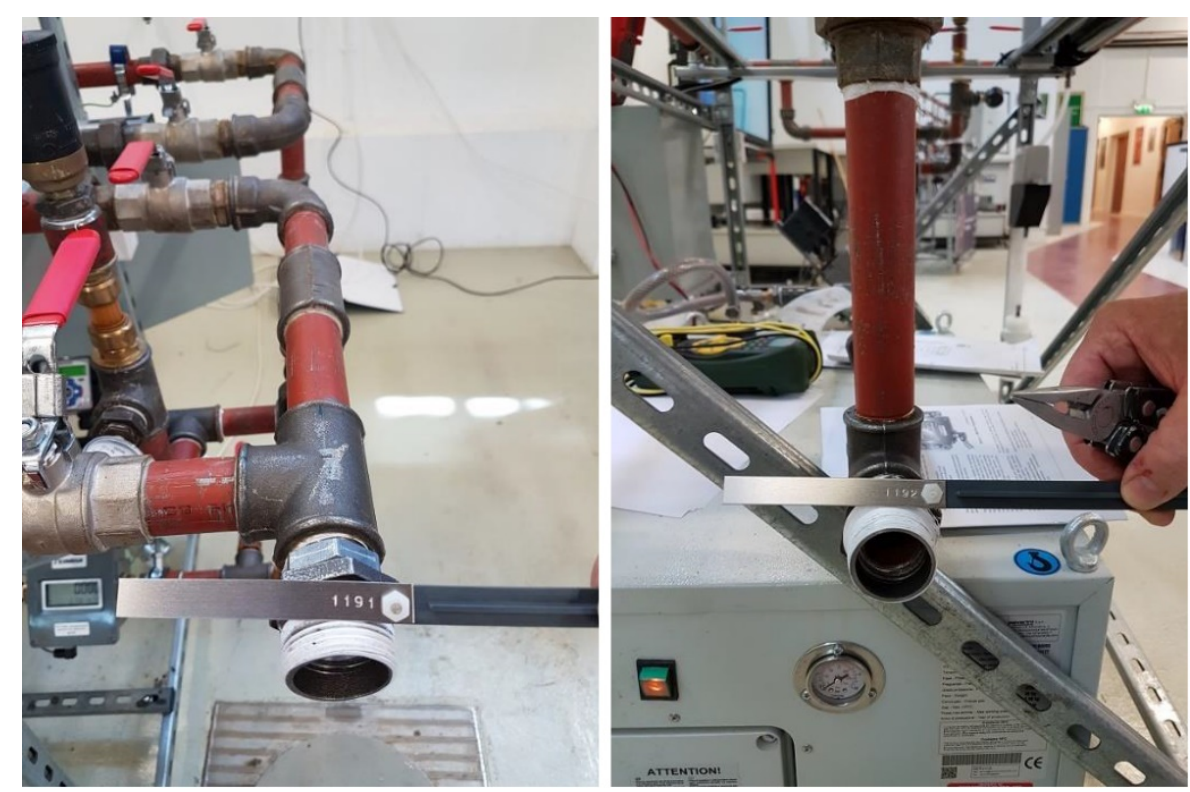

Figure 2: Mounting the coupons at two ends of the pipe network via holders

The LPR corrosion probe needs to be installed in a corrosion tee so that the probe tips are perpendicular to the exit flow (Figure 3). According to the manual of the LPR probe, it is recommended to allow 48 hours for the probe tips to acclimatise to the pipe network environment.

A customised software interface was also designed to illustrate logged data over a set period and present time values collected from the sensors. 


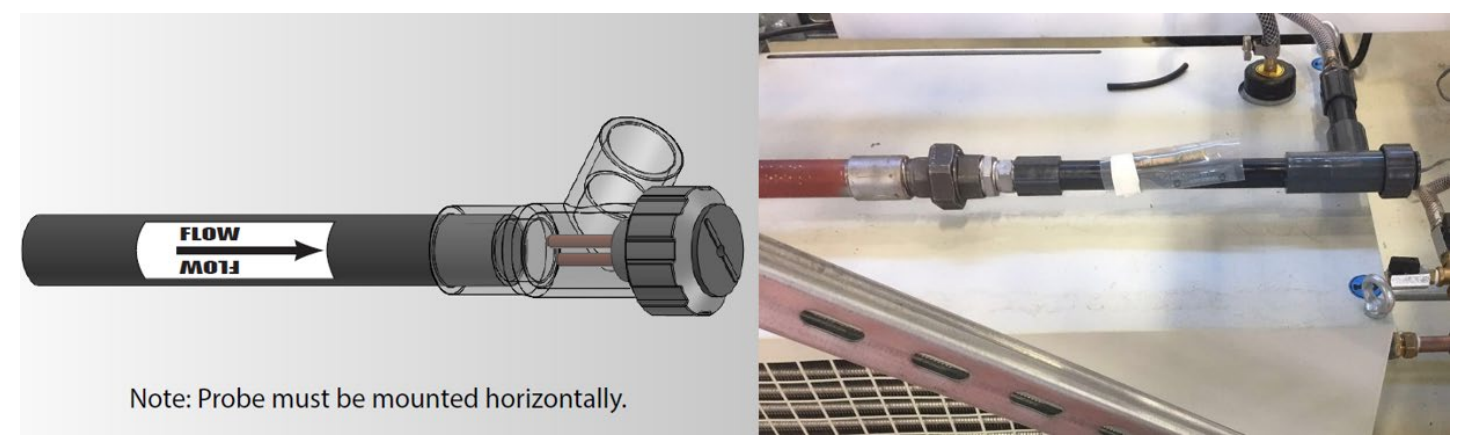

Figure 3: LPR probe installed on a tee joint on the rig

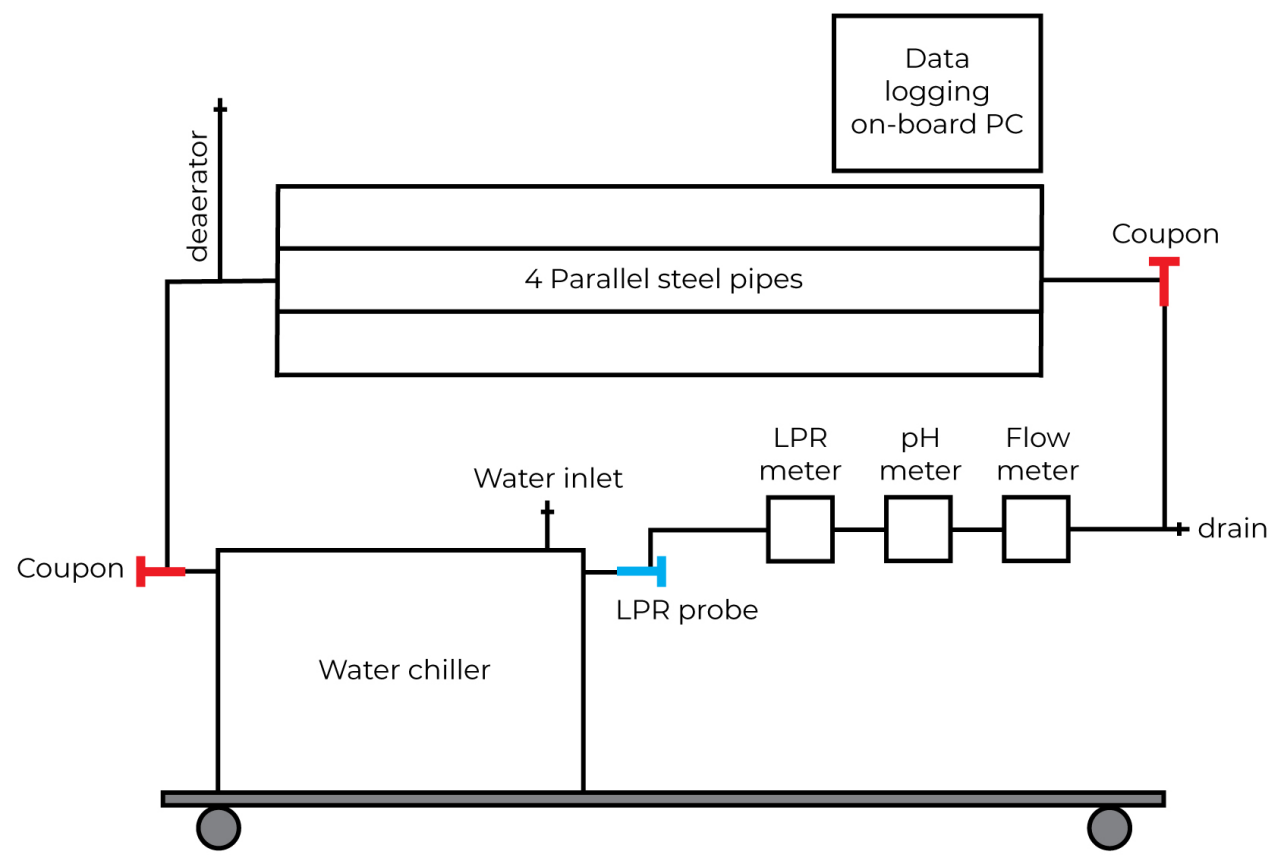

Figure 4: Schematic of the rig with coupon and LPR probe locations

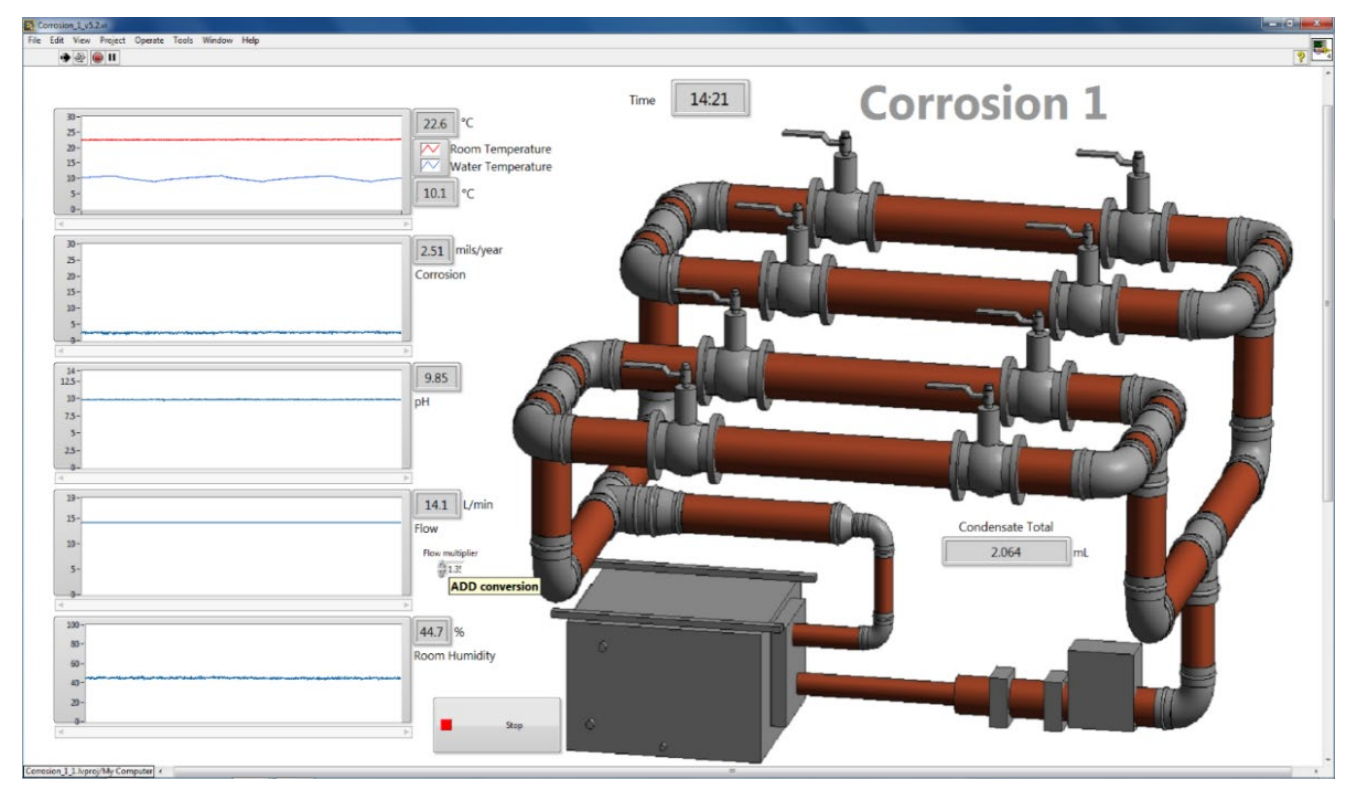

Figure 5: Snapshot of the custom interface built for logging and monitoring the sensors readings 
Table 3: Experiments executed in the study

\begin{tabular}{|c|c|c|c|}
\hline No. & Experiment & Duration & Water Temp $\left({ }^{\circ} \mathrm{C}\right)$ \\
\hline 1 & LPR Probe vs Coupons & 3 weeks & 23 \\
\hline 2 & Dirty LPR Probe & 6-month-old probe & $12-32$ \\
\hline 3 & Cleansed LPR Probe & same day & $12-33$ \\
\hline 4 & Two months after LPR cleanse & 2 months after cleanse & $12-34$ \\
\hline 5 & LPR in presence of Inhibitor & same day & $12-35$ \\
\hline
\end{tabular}

\section{Results and Analysis}

\subsection{Corrosion Rate Measured by Coupons and LPR probe}

Two strip coupons were installed in the pipe network for a total of 3 weeks. During this time period there was no feedback of corrosion rate in the pipe network. After the end of the three-week experimental run the coupon strips were unscrewed from the pipe network. When they were installed, they were polished strips of metal (see Figure 2) but after taking them out the strips had been highly corroded as shown in Figure 6. As the coupons work on weight loss method thus extreme care was needed to transfer them to protective packaging in order to be transferred to the coupon manufacturer's lab. After measuring weight loss and scaling it to a corrosion scale the manufacturer reported of a corrosion rate of $2.4 \pm 0.1$ mils/year.

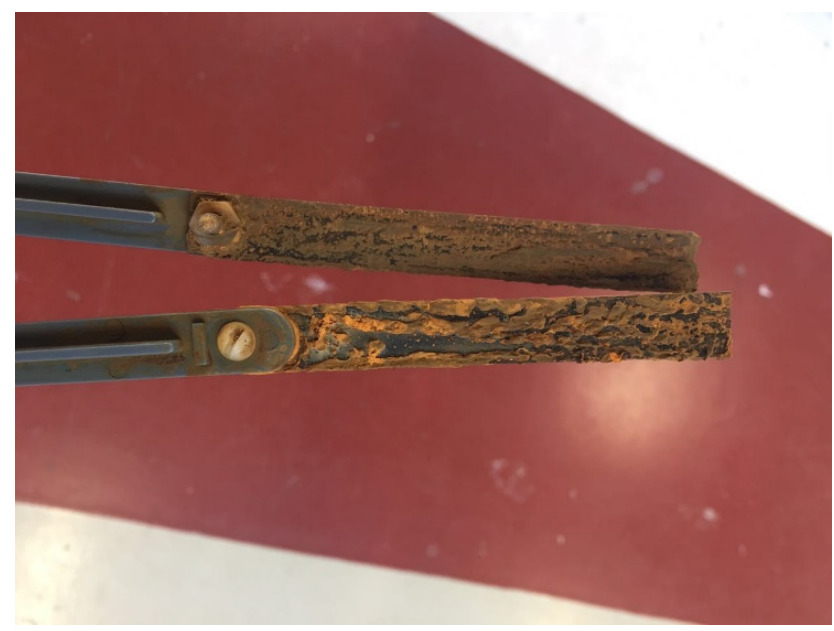

Figure 6: Coupons after the operation of corrosion experiment

Figure 7 shows the corrosion rate measured by the LPR probe over three weeks. Five gaps can be observed in the continuity of the readings. The 3 smaller gaps (which generally last 1-2 hours) are for measuring manually the $\mathrm{pH}$ of water in the HVAC tank. The two larger gaps are due to system shutdown due to Windows error on the PC logging the data. However, the overall trend can be observed of the corrosion rate decreasing and finally reaching a statistically steady state. The corrosion rate measured at the beginning of the experiment was the highest i.e. 15.75 mils/year whilst at the steady state it finally drops down to $2.2 \pm 0.4$ mils/year for the pipe rig under investigation. 
This makes the difference between the coupon method and the LPR probe $8.3 \%$ which in practical terms mean that over a service life of 50 years (manufacturer's service life guarantee) the predictions between the two methods will be off by 3 months which can be considered negligible. Thus, it can be concluded that the LPR method predicts the same corrosion rate as the coupon method. Additionally, the LPR probe has the added benefit of being able to present real time corrosion data of the pipe network so that remedial steps can be taken in time.

Table 4: Summary of LPR vs coupon corrosion prediction

\begin{tabular}{|c|c|c|}
\hline No. & Experiment & Results \\
\hline 1 & Corrosion Rate by coupons & $2.4 \pm 0.1$ mils/year \\
\hline 2 & Corrosion Rate by LPR probe & $2.20 \pm 0.01$ mils/year \\
\hline & Percentage difference & $8.30 \%$ \\
\hline
\end{tabular}

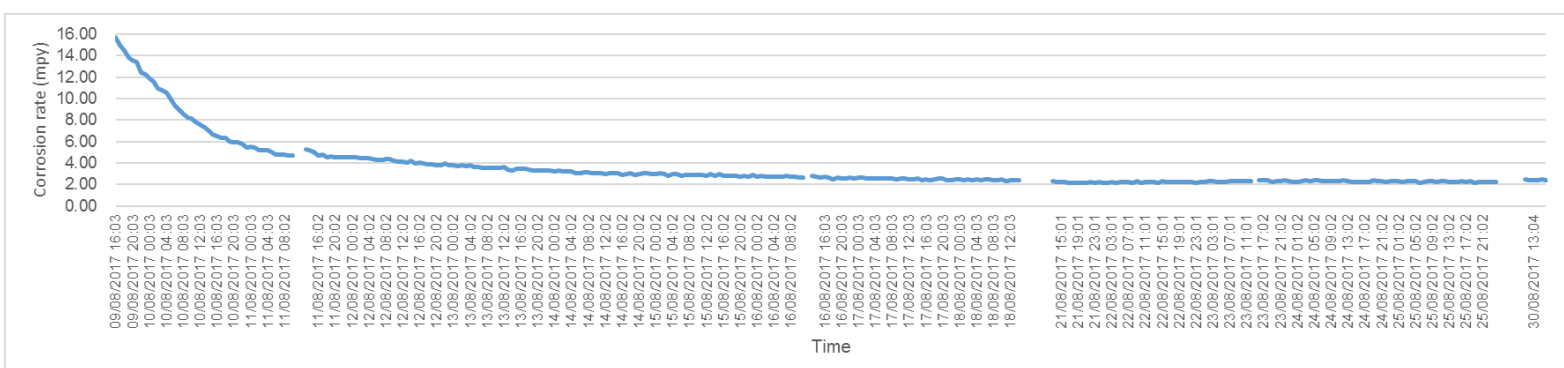

Figure 7: Corrosion rate measured by LRP probe over three weeks of experimental run

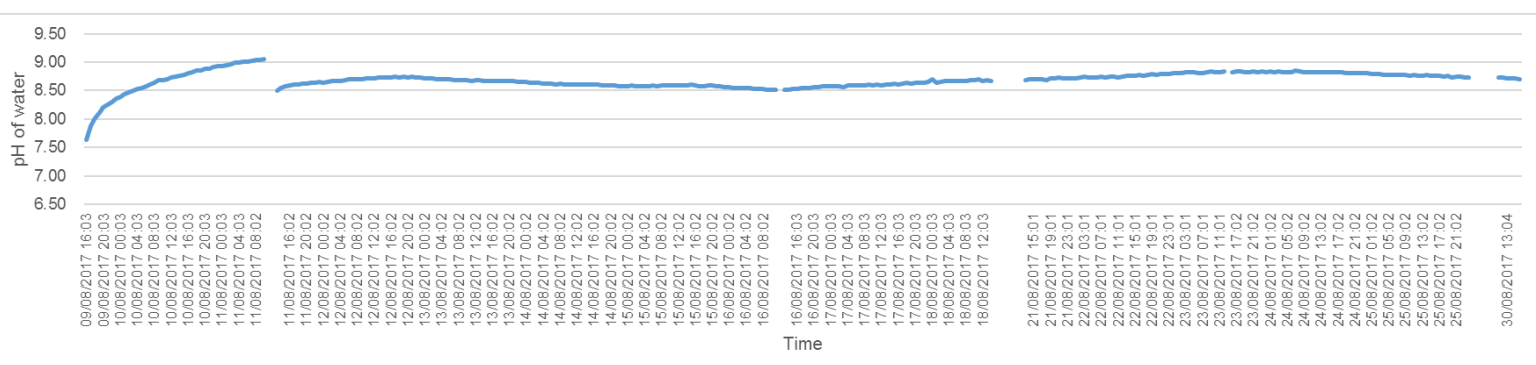

Figure 8: $\mathrm{pH}$ of water measured by $\mathrm{pH}$ probe during three weeks of experimental run

\subsection{Corrosion rates for in-situ conditions}

Corrosion is a complex phenomenon with numerous variables that influence its rate. In practice there are four conditions, related to surface condition that are often prevalent when measuring corrosion rates:

1. An old and dirty LPR probe: this is the scenario when a corrosion measuring probe has been installed in a system for a while and the two electrodes have become dirty and corroded over time. It is crucial to know how the degradation of the electrodes over time affect the corrosion prediction.

2. The probe after a cleanse: In order to improve the accuracy of the LPR probe the electrodes are at times cleansed. This involves scraping off the corrosion 
deposits with the help of fine sand paper and then cleaning the electrodes with alcohol. This method was also repeated in this research to understand how the prediction of an LPR probe is affected.

3. Few months after the probe has been cleaned: The reading after the electrodes are newly cleansed can be significantly different to when the electrodes become dirty again and hence another test is repeated two months after the electrodes were cleansed.

4. In the presence of an inhibitor: In order to mitigate corrosion in a pipe network, adding an inhibitor is common. However, the addition of a standard inhibitor in the pipe network may also affect the readings of the LPR probe. Hence the fourth scenario researched was the rig with an inhibitor added.

Another aspect worth investigating is the affect of temperature on corrosion rate. This can be of great value to the industry as to how an increase in temperature increases the rate of corrosion as well.

Results from the LPR probe of the corrosion rate predicted for the four mentioned scenarios over a range of temperatures are illustrated in Figure 7.

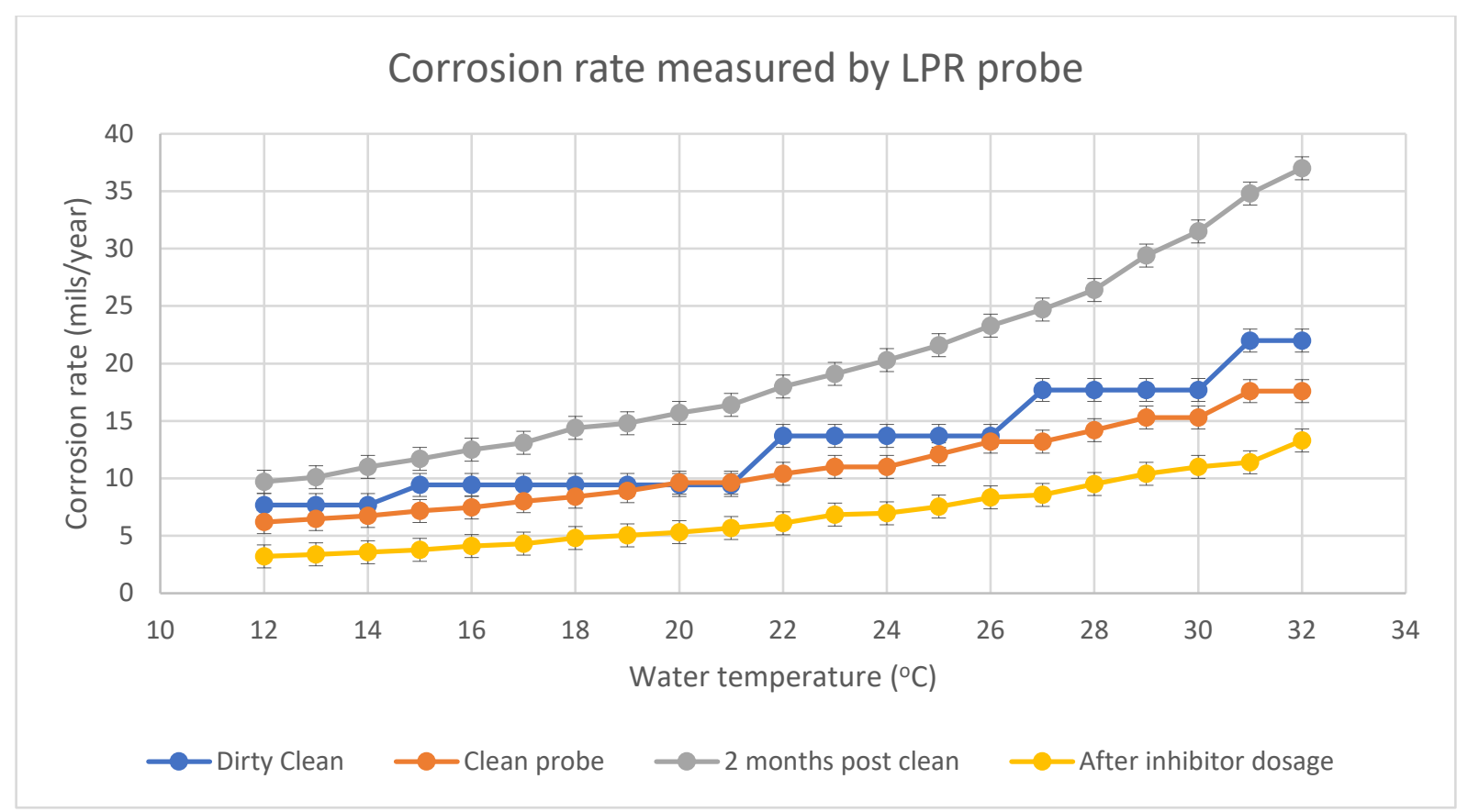

Figure 9: Corrosion rate predicted by an LPR probe for four typical in-situ scenarios

From Figure 7 it can be seen that before the probe is cleansed (blue line) for a water temperature of $12^{\circ} \mathrm{C}$ the corrosion rate is $7.7 \pm 0.4$ mils/year which increases to $22 \pm 0.4 \mathrm{mils} / \mathrm{year}$ for a temperature of $32^{\circ} \mathrm{C}$. This means that on average for every $1^{\circ} \mathrm{C}$ increase in water temperature the corrosion rates increased by $0.7 \pm 0.4$ mils/year or by $3.25 \%$.

When the probe was cleansed (red line) the corrosion rate is predicted to be $6.2 \pm 0.4 \mathrm{mils} /$ year at $12^{\circ} \mathrm{C}$ which is approximately $20 \%$ less than when the electrodes 
were dirty. It is expected as the electrodes are cleansed from corrosion deposits the corrosion predicted by the probe will be lower. At water temperature of $32^{\circ} \mathrm{C}$ the corrosion rate predicted is $17.6 \pm 0.4$ mils/year which is again $20 \%$ less than when the probe was dirty. Hence it can be concluded that the dirty probe was over predicting corrosion rate by $20 \%$ compared to a clean probe. For every $1^{\circ} \mathrm{C}$ degree increase in temperature the corrosion rate increased by $0.6 \mathrm{mils} /$ year which is $3.2 \%$.

For the scenario when two months had elapsed after the probe was cleansed, a corrosion rate of $9.7 \pm 0.4 \mathrm{mils} / \mathrm{year}$ was predicted for water at $12^{\circ} \mathrm{C}(36 \%$ higher than when the probes were new). For the other end of the temperature spectrum, at $32^{\circ} \mathrm{C}$ the corrosion rate predicted was $37 \pm 0.4$ mils/year ( $52 \%$ higher than when the probes were new). And for each $1^{\circ} \mathrm{C}$ increase in water temperature the corrosion rate increased by $1.4 \mathrm{mils} / \mathrm{year}$ or $3.7 \%$ on average.

Lastly, in the case where an inhibitor is added to the pipe network the corrosion rate dropped down to $3.2 \pm 0.4 \mathrm{mils} / \mathrm{year}$ which is a $50 \%$ drop in corrosion rate compared to the case where there was no inhibitor. At the higher temperature of $32^{\circ} \mathrm{C}$ the corrosion rate predicted was $13.3 \pm 0.4 \mathrm{mils} / \mathrm{year}$ ( $25 \%$ drop in corrosion rate compared to the absence of an inhibitor dosage). An increase of 0.5 mils/year (or $3.8 \%$ ) is observed for every $1^{\circ} \mathrm{C}$ increase in temperature.

Table 5: Summary of LPR probe results for in-situ scenarios

\begin{tabular}{|c|c|c|c|c|c|c|}
\hline \multirow{2}{*}{ Test scenario } & \multicolumn{2}{|l|}{} & \multicolumn{2}{c|}{} & $\begin{array}{c}\text { increase in corrosion for } \\
\text { Water temp }\end{array}$ & \multicolumn{2}{c|}{$\begin{array}{c}\text { Corrosion Rate } \\
\text { temperature }\end{array}$} \\
\cline { 2 - 8 } & $12^{\circ} \mathrm{C}$ & $32^{\circ} \mathrm{C}$ & $12^{\circ} \mathrm{C}$ & $32^{\circ} \mathrm{C}$ & mils/year & $\%$ \\
\hline Dirty probe & 7.7 & 22.0 & $7.7 \pm 0.4$ & $22.0 \pm 0.4$ & 0.7 & 3.3 \\
\hline Cleansed probe & 6.2 & 17.6 & $6.2 \pm 0.4$ & $17.6 \pm 0.4$ & 0.6 & 3.2 \\
\hline 2 months after cleanse & 9.7 & 37.0 & $9.7 \pm 0.4$ & $37.0 \pm 0.4$ & 1.4 & 3.7 \\
\hline Inhibitor added & 3.2 & 13.3 & $3.2 \pm 0.4$ & $13.3 \pm 0.4$ & 0.5 & 3.9 \\
\hline Average & 6.7 & 22.4 & 22.5 & 22.4 & 0.8 & 3.5 \\
\hline
\end{tabular}

\section{Summary and Conclusions}

The highest corrosion occurs at the beginning when pipes are new and have no means of protection against corrosion. As the new pipe metal corrodes, a scale is formed on the inside surface which acts as a barrier against corrosion, causing a decrease in corrosion rate to a steady state value.

Comparing the industry standard coupon method with the relatively new Linear Polarisation Resistance (LPR) method it was found that results from both techniques had a mean difference of $8.3 \%$ which in practical terms equates to approximately 3 months over a 50 -year service life of the pipe network. Thus, it can be concluded that both the coupon and LPR method give similar results although the LPR method has the added benefit of presenting real-time corrosion rate whilst for the coupon method 
the results are only acquired after the fact. A coupon method is also very sensitive to how the coupons are installed/removed from the rig and transported to/from the lab as it is based on weight loss method. The coupons are also relatively cheaper than an LPR probe though they are a one time use only device whilst an LPR probe can be employed many times.

Employing the LPR probe further, four in-situ scenarios were simulated to investigate the effects it had on the corrosion rate. A dirty pair of LPR electrodes that had corrosion debris deposited on them differed in the corrosion rate by $20 \%$ compared to clean/new electrodes. Also, an LPR probe that was tested 2 months after it was cleansed differed in the corrosion by $44 \%$ on average compared to a newly cleansed LPR probe. And finally, a pipe network that was dosed with an inhibitor showed a 50\% drop in corrosion rate at lower temperatures (around $10^{\circ} \mathrm{C}$ ) and $25 \%$ drop at higher temperatures (around $30^{\circ} \mathrm{C}$ ). This thus means that the LPR probe, although more dynamic compared to coupons, is highly sensitive to conditions it is exposed to. This highlights a limitation of LPR probes which are intended to be installed in HVAC systems for long periods of time but need constant maintenance and calibration.

When trying to establish a relationship between temperature and corrosion it was found that for each degree $1^{\circ} \mathrm{C}$ increase in temperature the corrosion rate increased by $3.5 \%$ on average. This confirms that it is crucial during the design stage to understand how rise in water temperature in an HVAC system can affect the corrosion rate of the pipe network.

It is needs to be acknowledged at this stage that predicting an exact corrosion rate should not be the aim as these methods have inherent uncertainty. For example, the coupon method relies on weight loss to determine corrosion rates. The corroded coupon however will lose some debris when it is unmounted from the system, carried to the lab, man handling etc. Additionally, the coupons often have slightly different material and physical properties compared to the properties of the pipes that constitute the HVAC network. Similarly, an LPR probe reading is based on translating changes in electric potential to a corrosion rate scale which is developed by the LPR probe manufacturers using empirical methods. Thus, the aim should rather be to use these techniques more for comparative purposes, system monitoring, detecting unusual activity etc.

\section{The future - Advantages of continuous monitoring}

As has been discussed above, it is clear that corrosion of steel pipework is influenced by many factors. These range from the surface condition of the steel itself (presence or not of an oxide layer, and passivation effects due to inhibitors); the composition and nature of the water $(\mathrm{pH}$, conductivity and dissolved oxygen level); and the environmental conditions (temperature and flow). Modern monitoring techniques now make it possible to measure and record these in real time and forward the results via the cloud where they can be viewed on laptops and mobile devices. Real-time and 
continuous remote monitoring has huge advantages over the use of corrosion coupons for obvious reasons (instantaneous readings, no site visits, multiple parameters etc). Alarms can also be set so that an operator is immediately informed of adverse conditions before damage occurs, rather than having to wait to see the results from coupon tests. Furthermore, by measuring the influencing factors, the root cause of any corrosion can be determined in order to inform remedial action.

This paper has discussed the merits of the LPR technique to measure corrosion rates. LPR sensors are readily available and can indeed be used with remote monitoring technology. However, the high prices make them commercially unattractive for use in HVAC applications. For this reason, alternative lower cost corrosion sensors are becoming available, which when used in conjunction with other sensors (dissolved oxygen, conductivity, flow, $\mathrm{pH}$, temperature, pressure etc) provide a complete picture of the corrosion conditions within such systems. Further studies are underway and will from the basis of future technical papers.

\section{References}

BROWN, R. (2013). Water Treatment for Closed Heating and Cooling Systems. BSRIA.

DUNCAN, J. (2011). High Cost of Building Services Corrosion, BUILD 123, pp $52-53$

FONTANA, M. 1987. Standard Expressions for Corrosion Rate, Corrosion Engineering, 171-174.

FONTANA, M. G. 2005. Corrosion engineering, Tata McGraw-Hill Education.

HOAR, T. P. 1976. Review Lecture - Corrosion of metals: its cost and control. Proceedings of the Royal Society of London. A. Mathematical and Physical Sciences, 348.

LAMBERT, P. 2001. Corrosion mechanisms-an introduction to aqueous corrosion. Corrosion Prevention Association, Technical Note.

Department for Business, Energy, \& Industrial Strategy 2018. Energy Consumption in the

UK. https://assets.publishing.service.gov.uk/government/uploads/system/uploads/ attachment_data/file/729317/Energy_Consumption_in_the_UK_ECUK_201 8.pdf. 